\title{
Systemic Cryotherapy Influence of Low Temperatures on Selected Physiological Parameters
}

\author{
Z. DAMIJAN ${ }^{a, *}$ AND A. UhRYŃSKI ${ }^{b}$ \\ ${ }^{a}$ AGH University of Science and Technology, Faculty of Mechanical Engineering and Robotics \\ Department of Mechanics and Vibroacoustics, al. A. Mickiewicza 30, 30-059 Krakow, Poland \\ ${ }^{b}$ AGH University of Science and Technology, Faculty of Mechanical Engineering and Robotics \\ Department of Machine Design and Technology, al. A. Mickiewicza 30, 30-059 Krakow, Poland
}

\begin{abstract}
The work presents the research and analysis of the influence of low temperatures on selected physiological parameters of a human being. The research was conducted in the 20th Military Healing and Rehabilitation Hospital SPZOZ in Krynica-Zdrój, Poland. Systematic cryotherapy is a procedure during which the whole body, including the head, is exposed to very low temperature (about $-110^{\circ} \mathrm{C}$ ) in a short time (no more than $3 \mathrm{~min}$ ). The procedure is of a stressful nature; the exposure of almost naked body to a temperature not met in human natural environment causes a sudden mobilization of all the organism defence forces which is used in treatment, sport training and biological renewal. The reaction to extreme cold takes form of a short contraction which is followed by long-lasting - a few hours - dilatation of skin blood vessels. It is accompanied by analgesic and anti-inflammatory effect, relaxation of bronchi muscles, tendency to decrease oedemas and exudates, increase in immunity and mood, including even the euphoria feeling. The research included 20 people after having signed the agreement and excluding any contraindications. The research was carried on following the criteria of the estimate of research reliability according to Jadad randomisation. Every day, during 14 weekdays, after and before the procedure $\left(3 \mathrm{~min}\right.$ stay in a cryochamber, $\left.t=-110^{\circ} \mathrm{C}\right)$ the measurement of selected parameters were taken, such as: systolic and diastolic pressure, pulse, temperature in aural canal, body mass, fatty tissue and changes of outer body temperatures (thermo-vision analysis). On the basis of the results and conducted analysis one can state that systemic cryotherapy causes the following changes: statistically significant increase of systolic pressure, diastolic pressure, fatty tissue, significant drop of pulse, deep temperature in aural canal and outer body temperature in analysed thermograms. The results were developed statistically using standard methods in accordance with algorithms of statistical inference. The aim of the work is the research on how a short-term exposure to cold changes the outside temperature of the front of a body, and answer to the question if the limb heat - the left and right side - reacts to heat identically. The work introduces biophysical research of the influence of low temperatures on thermodynamic changes in a human being. The results presented are not often met in specialist literature.
\end{abstract}

PACS: 07.20.Mc

\section{Introduction}

The application of cold is the oldest method of physiotherapy. The earliest remark concerning it can be found in the papyrus dating back to 2500 B.C. In order to cool the tissues cold water, snow and ice were used. It was known since long that cold helps in severe inflammation and prevents the post-traumatic haematoma. Hipocrates (460-377 B.C.) recommended compresses of ice or snow. Awicenna (980-1070) used snow and icy water to anaesthetize. Jean Larrey, Napoleon's surgeon, described in his diaries painless amputations on battle fields conducted in severe frost.

The small bags with ice, used in medical treatment were introduced over 100 years ago. Technological progress created new opportunities; enabled to make a

* corresponding author; e-mail: damijan@imir.agh.edu.pl synthesis and production of ether, ethyl chloride, dry ice etc. Also, it has been possible for a long time to produce very low temperatures $\left(-195.8^{\circ} \mathrm{C}\right.$ which is the temperature in which liquid nitrogen boils). Such low temperatures were used before in cryo-destruction, namely, to freeze selected tissues which leads to their destruction. Another phase of progress was performed in the 80's of the 20th century. Doctor Toshimo Yamauchi published his work in 1978 concerning the usage of liquid nitrogen steam and cooled air to over $-100^{\circ} \mathrm{C}$ to treat patients who suffer from rheumatoid arthritis. In his work he proved that low temperatures are not only used to destroy tissues - cryo-destruction - but also to produce positive physiological reactions of the organism to cold. A new term was invented - cryo-stimulation. Reinhard Fricke dealt with it in Europe. He introduced a new method of treatment: a systemic action of cold in a cryo-chamber, first cooling with liquid nitrogen and then with cold air $[1,2]$. 
Systemic cryotherapy in Poland was introduced by Zdzisław Zagrobelny in 1989. He used a cryochamber with liquid nitrogen built by Zbigniew Raczkowski from the Institute of Low Temperatures and Structural Studies, PAS, in Wrocław. In the year 2002 there were 5 cryochambers with liquid nitrogen and one working without it, cooling the temperature of air to $-110^{\circ} \mathrm{C}$, applying the rules used in contemporary freezers (Hotel Senator in Dźwirzyno, Poland) [1, 2].

Systematic cryotherapy is a procedure in which the whole body (including head) is exposed to very low temperature (above $-110^{\circ} \mathrm{C}$ ) in a short time (no more than $3 \mathrm{~min}$ ). The procedure is of a stressful nature; the exposure of almost naked body to a temperature not met in human natural environment causes a sudden mobilization of all the organism defence forces which is used in treatment, sport training and biological renewal. The reaction to extreme cold takes form of a short contraction which is followed by long-lasting - a few hours — dilatation of skin blood vessels. It is accompanied by analgesic and anti-inflammatory effect, relaxation of bronchi muscles, tendency to decrease oedemas and exudates, increase in immunity and mood, including even the euphoria feeling. That is followed by the greater output of stress hormones $[2,3]$.

As we can see systemic cryotherapy has a wide usage in treating diseases ranging from osteoarthrosis, rheumatism, neurological illness, depression, osteoporosis, to post-traumatic and overburdening condition of motion organs.

The therapy should not be used with advanced insufficient function of heart and vessels, irregular hypertension, fever condition, pathological reactions to cold: both local and general, severe inflammatory state, lack of emotional balance and claustrophobia tendency [3-6].

The right clothes for the therapy consist of: swimsuit, warm socks, gloves, ear-muffs, boots on wooden soles, a mask for mouth and nose. After entering the cryochamber the patients follows the operators' instructions. After leaving it they have to take $30 \mathrm{~min}$ gymnastics focused on the medical condition they have and supervised by the physiotherapeutist.

The main state consultant in balneology and physical medicine established the following parameters of systemic cryotherapy procedure in a 1-person chamber physiological parameters of a human being. In the 20th Military Healing and Rehabilitation Hospital SPZOZ in Krynica-Zdrój the cryo-chamber houses 4 people, it is cooled by air and a 15-20 min break between the procedures is necessary to cool it (Fig. 1). Due to these facts, estimated periods of time are given in brackets (Table I).

\section{Methodology of research}

The research included 20 people after having signed the agreement and excluding any contraindications. The research was carried on following the criteria of the estimate of research reliability according to the Jadad randomisation. Every day, during 14 weekdays, after and

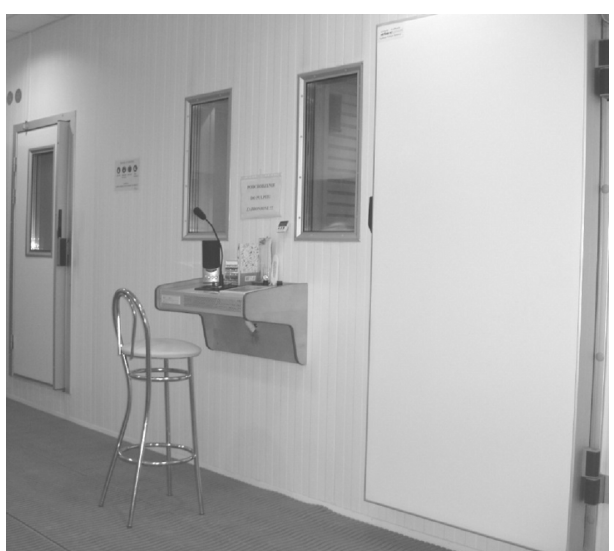

Fig. 1. The cryo-chamber in the 20th Military Healing and Rehabilitation Hospital in Krynica-Zdrój, Poland.

TABLE I

Standard parameters of the systemic cryotherapy procedure [4].

\begin{tabular}{l|c}
\hline \hline Procedure time [min] & $2-3$ \\
\hline $\begin{array}{l}\text { Minimum time to prepare the equipment } \\
\text { for the procedure [min] }\end{array}$ & 2 \\
\hline $\begin{array}{l}\text { Minimum time of direct contact } \\
\text { of patients and staff [min] }\end{array}$ & $2-3$ \\
\hline $\begin{array}{l}\text { Average number of procedures } \\
\text { on one procedure stand during one hour }\end{array}$ & $13(6-12)$ \\
\hline $\begin{array}{l}\text { Average number of procedure stands } \\
\text { serviced by one person during one hour }\end{array}$ & $1(1)$ \\
\hline $\begin{array}{l}\text { Maximum daily }(7 \mathrm{~h}) \text { number of procedures } \\
\text { serviced by one person }\end{array}$ & $91(84)$
\end{tabular}

before the procedure ( $3 \mathrm{~min}$ stay in a cryo-chamber, $t=-110^{\circ} \mathrm{C}$ ) the measurement of selected parameters were taken, such as: systolic and diastolic pressure, pulse, temperature in aural canal, body mass, fatty tissue and thermo-visial photos. Figure 2a shows the body parts analysed. Figure $2 \mathrm{~b}$ shows average body temperatures before and after the procedure.
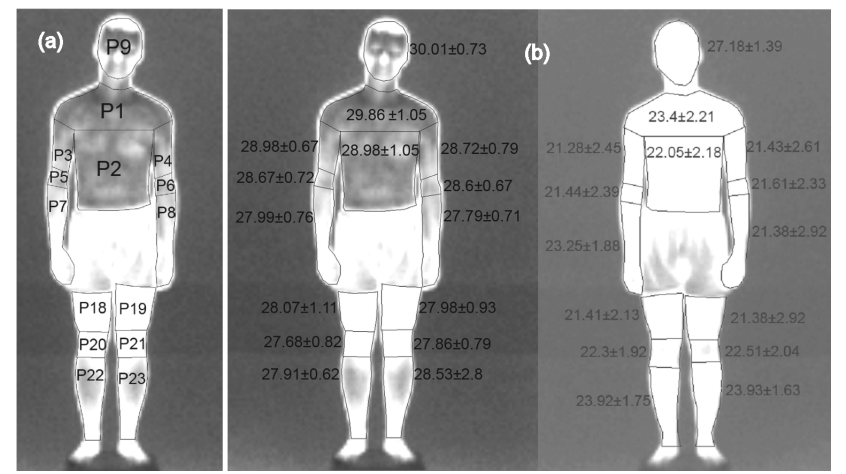

Fig. 2. a) Body parts which were tested. b) Body temperatures before and after the procedure. 
The results were analyzed concerning statistics using Statistica 7.1 of StatSoft for which AGH has got a license. For the sake of the analysis the significance level was $p=0.05$ (standard value in biological sciences). For the sake of the analysis the nonparametric KolmogorovSmirnov tests were used, together with Lilliefors and W-Shapiro-Wilk ones (standard tests to measure normal distribution).

When the variables analysed had a normal distribution, then in inner-group analysis the test probability of difference significance was conducted by $T$ test for dependent groups (as two groups are compared, measurement scales of variables are quantitative and the size of a try $<30$ ). When the variables analysed did not have a normal distribution the Wilcoxon testor Brown-Forsythe or Mann-Whitney ones were used. The zero hypothesis for every variable was as follows: exposure of a human body to low temperature does not cause the changes of dependent variable.

According to the analysis of the results one can state that except "P, K" all the variables have normal distribution. The results of the statistic analysis were presented in Tables II and III.

Analysis of difference significance of physiological variables.

TABLE II

\begin{tabular}{l|c|c|c|c}
\hline \hline \multirow{2}{*}{ Variables } & \multicolumn{4}{|c}{$T$ test for dependent groups } \\
\cline { 2 - 5 } & Average & Stand. deviation & Difference & $p$ \\
\hline CS_P [mmHg] & 119.96 & 9.94 & 8.60 & $p<0.005$ \\
CS_K [mmHg] & 128.56 & 12.15 & 4.82 & $p<0.009$ \\
\hline CR_P [mmHg] & 78.62 & 6.73 & & \multirow{2}{*}{$p<10^{-4}$} \\
CR_K [mmHg] & 83.23 & 8.20 & -6.76 & \multirow{2}{*}{$0<0.016$} \\
\hline Pulse_P [1/min] & 75.93 & 9.73 & -0.20 & \multirow{2}{*}{0.5570} \\
Pulse_K [1/min] & 69.17 & 0.42 & 0.11 & \multirow{2}{*}{$p<10^{-5}$} \\
\hline T_P [ $\left.{ }^{\circ} \mathrm{C}\right]$ & 35.99 & 0.44 & 1.17 &
\end{tabular}

\section{Conclusions}

Following the experiment results and conducted analysis (Fig. 2b) we can state that a stay in a cryochamber results in changes of selected physiological parameters.

The increase in blood pressure seems to be justified as the cryo-stimulation procedure is stressful to the organism; mobilising its defence forces. The increase in fatty tissue amount is the defence reaction to cold exposure or is an effect of a change in tissue resistance (the research on that needs another experiment). The fall of pulse results in volumetric arterial dilatation, which correlates with dilatation of skin blood vessels. The drop of temperature in aural canal and the outside body temperature signifies the cooling of the organism which is a natural reaction to cold exposure.

Following the analysis of Table III one can state that before the exposure to cold the temperatures of analysed - symmetric - areas of limbs of the right side of the body have higher temperatures than the left side, and the greatest drops of temperature for the body front appear in the upper part of the trunk (head, shoulders, stomach area and arms).

It is interesting to notice that for the symmetrical body parts (arms and legs) one can observe greater temperature drops (excluding shins). Exposure to cold results in lower temperature of right side limbs than left side ones (excluding elbow and shank).

Research presented in this work is part of a long-lasting program concerning the trials to create detailed thermal maps for healthy persons. The results of the research are a good starting point and may be useful in optimization of cryogenic temperatures, illness diagnosis and monitoring of treatment and rehabilitation.

The researchers of the above study had the permission from Bioethics Commission of Medical Academy in Łódź, Poland. The applied stimulus was safe. The participants were all insured. 
TABLE III

Analysis of difference significance of thermovision variables.

\begin{tabular}{|c|c|c|c|c|}
\hline \multirow{2}{*}{ Variables } & \multicolumn{4}{|c|}{$T$ test for dependent groups } \\
\hline & Average & Stand. deviation & Difference & $p$ \\
\hline $\mathrm{P} 1 \_\mathrm{P}$ & 29.86 & 1.05 & \multirow{2}{*}{-6.46} & \multirow{2}{*}{$p<10^{-6}$} \\
\hline $\mathrm{P} 1 \_\mathrm{K}$ & 23.40 & 2.21 & & \\
\hline $\mathrm{P} 2 \_\mathrm{P}$ & 28.98 & 1.49 & \multirow{2}{*}{-6.93} & \multirow{2}{*}{$p<10^{-6}$} \\
\hline $\mathrm{P} 2 \_\mathrm{K}$ & 22.05 & 2.18 & & \\
\hline P3_P & 28.98 & 0.67 & \multirow{2}{*}{-7.70} & \multirow{2}{*}{$p<10^{-7}$} \\
\hline P3_K & 21.28 & 2.45 & & \\
\hline $\mathrm{P} 4 \_\mathrm{P}$ & 28.72 & 0.79 & \multirow{2}{*}{-7.29} & \multirow{2}{*}{$p<10^{-6}$} \\
\hline $\mathrm{P} 4 \_\mathrm{K}$ & 21.43 & 2.62 & & \\
\hline $\mathrm{P} 5 \_\mathrm{P}$ & 28.68 & 0.73 & \multirow{2}{*}{-7.23} & \multirow{2}{*}{$p<10^{-7}$} \\
\hline $\mathrm{P} 5 \_\mathrm{K}$ & 21.45 & 2.40 & & \\
\hline P6_P & 28.60 & 0.67 & \multirow{2}{*}{-6.99} & \multirow{2}{*}{$p<10^{-7}$} \\
\hline P6_K & 21.61 & 2.34 & & \\
\hline $\mathrm{P} 7 \_\mathrm{P}$ & 27.99 & 0.76 & \multirow{2}{*}{-4.74} & \multirow{2}{*}{$p<10^{-6}$} \\
\hline $\mathrm{P} 7 \_\mathrm{K}$ & 23.25 & 1.88 & & \\
\hline $\mathrm{P} 8 \_\mathrm{P}$ & 27.79 & 0.72 & \multirow{2}{*}{-4.53} & \multirow{2}{*}{$p<10^{-6}$} \\
\hline P8_K & 23.26 & 1.80 & & \\
\hline $\mathrm{P} 9 \_\mathrm{P}$ & 30.01 & 0.73 & \multirow{2}{*}{-2.83} & \multirow{2}{*}{$p<10^{-6}$} \\
\hline $\mathrm{P} 9 \_\mathrm{K}$ & 27.18 & 1.39 & & \\
\hline P18_P & 28.08 & 1.12 & \multirow{2}{*}{-6.67} & \multirow{2}{*}{$p<10^{-8}$} \\
\hline $\mathrm{P} 18 \_\mathrm{K}$ & 21.41 & 2.13 & & \\
\hline $\mathrm{P} 19 \_\mathrm{P}$ & 27.98 & 0.93 & \multirow{2}{*}{-6.60} & \multirow{2}{*}{$p<10^{-7}$} \\
\hline P19_K & 21.39 & 2.14 & & \\
\hline $\mathrm{P} 20 \_\mathrm{P}$ & 27.69 & 0.82 & \multirow{2}{*}{-5.38} & \multirow{2}{*}{$p<10^{-7}$} \\
\hline P20_K & 22.31 & 1.92 & & \\
\hline $\mathrm{P} 21 \_\mathrm{P}$ & 27.86 & 0.80 & \multirow{2}{*}{-5.35} & \multirow{2}{*}{$p<10^{-7}$} \\
\hline $\mathrm{P} 21 \_\mathrm{K}$ & 22.51 & 2.04 & & \\
\hline P22_P & 27.91 & 0.63 & \multirow{2}{*}{-3.98} & \multirow{2}{*}{$p<10^{-7}$} \\
\hline P22_K & 23.93 & 1.75 & & \\
\hline P23_P & 28.53 & 2.80 & \multirow{2}{*}{-4.60} & $p<10^{-4}$ \\
\hline P23_K & 23.93 & 1.63 & & \\
\hline
\end{tabular}

\section{Acknowledgments}

The research was done within the project no. 11.11.130.119, 11.11.130.887.

\section{References}

[1] A. Sieron, G. Cieślar, The Usage of Cold in Medicine - Cryo-Surgery and Cryo-Therapy, $\alpha$-Medica Press, Bielsko-Biała 2003.

[2] A. Straburzyńska-Lupa, G. Straburzyński, Physio- Therapy with Clinical Elements, Medical Publishers PZWL, Warszawa 2008 (in Polish).
[3] I. Ponikowska, D. Ferson, Modern Therapy in Health Resorts, Medi-Press, Warszawa 2008.

[4] I. Ponikowska, Compendium of Balneology. Directions and Tips for Treatment in Health Resorts, Adam Marszałek Publishers, Torun 2002 (in Polish).

[5] P. Krzyworzeka, A. Uhryński, Acta Bio-Optica Inform. Med. 15, 23 (2009) (in Polish).

[6] Z. Damijan, A. Uhryński, Acta Phys. Pol. A 118, 35 (2010). 